\title{
Extraction, Evaluation and Structure Elucidation of Bioactive Metabolites of Lactobacillus helveticus CNRZ 32
}

\author{
Gamal A. Ibrahim ${ }^{1(i)}$, Osama M. Sharaf ${ }^{2}$ (i), Mamdouh S. Al-Gamal ${ }^{3}$, Ahmed M. Youssef ${ }^{4}$ (D), Nadia \\ M. Dabiza $^{2}$ (i), Mohamed F. El-Ssayad ${ }^{2, *}$ (D)
}

1 Dairy Science Dept., (Dairy Microbiol. Lab.), National Research Centre, 33 El-Bohouth St. (Former El-Tahrir St.) Dokki, Giza, Egypt. Email: gamalwahab2015@gmail.com;

2 Dairy Science Dept., (Dairy Microbiol. Lab.), National Research Centre, 33 El-Bohouth St. (Former El-Tahrir St.) Dokki, Giza, Egypt. Email: sharafosama@yahoo.com (O.M.S.); nadiadabiza2005@yahoo.com (N.M.D.); sayad.nrc2012@gmail.com (M.F.ES)

3 Botany and Microbiology Dept., Faculty of Science (Boys), Al-Azhar University, Cairo, Egypt. Email: sayad.nrc2012@yahoo.com;

4 Packing and Packaging Materials Dept., National Research Centre, 33 El-Bohouth St. (Former El-Tahrir St.) Dokki, Giza, Egypt. Email: amyoussef72@yahoo.com;

* Correspondence sayad.nrc2012@gmail.com;

Received: 7.06.2020; Revised: 27.06.2020; Accepted: 29.06.2020; Published: 3.07.2020

Abstract: There is no previous work that utilizes the multi-solvent extraction and structure elucidation of Lactobacillus helveticus cell-free supernatant (CFS). In this study, the CFS of Lb. helveticus CNRZ 32 was extracted by ethyl acetate, diethyl ether, dichloromethane, and n-hexane solvents. The extracts of considerable antimicrobial activities were characterized through GC/MS clarify metabolic profiles, TLC for compounds separation, and bio-autography to determine the number and $R_{f}$ of effective compounds. Ethyl acetate extract possessed the strongest effect on all tested pathogens with inhibition diameter reached $38 \mathrm{~mm}$ in the case of Staphylococcus sciuri, while Diethyl ether and Dichloromethane extracts came secondly. The extract of Ethyl acetate mainly included butyl lactate with area \% (59.45), while 9,12-Octadecadienoic acid (Z,Z)-, methyl ester and different health beneficial compounds were identified in both Diethyl ether and Dichloromethane extracts. Due to the strong synergism among Chitosan Nanoparticles and different extracts, the MIC values were lowered by about $20-50 \%$.

Keywords: Lactobacillus helveticus CNRZ 32; GC/MS; Bio-autography; Chitosan Nanoparticles; MIC.

(C) 2020 by the authors. This article is an open-access article distributed under the terms and conditions of the Creative Commons Attribution (CC BY) license (https://creativecommons.org/licenses/by/4.0/).

\section{Introduction}

Extraction of natural bioactive compounds using organic solvents was found to be more interested in higher plants [1]. Lactic acid bacteria have a great contribution to improving human health. Many researchers have evidenced the positive contribution in microbial interactions with many foodborne pathogenic and spoilage microorganisms. Authors reported the inhibitory behavior of LAB either through the production of antimicrobial metabolites, what so-called "metabolic secretion" [2], or in the form of starter cultures through competitive exclusion against bacteria and fungi [3,4]. Regarding the immunomodulation effect, [5] demonstrated LAB-induced synergistic activation of intestinal Plasmacytoid dendritic cells (pDCs) and the induction of the expression of anti-viral genes in the lung by the oral administration of LC-Plasma in combination with emulsifiers in vivo. Also, their metabolic 
secretion includes the production of a wide variety of metabolites such as organic acids, bacteriocins [6], some volatile compounds, and antifungal esters [7]. The extraction of antimicrobial substances may be conducted through a wide range of organic solvents. By using Ethyl acetate extraction, [8] successfully isolated 2- (2-1 mino-1- hydroxyethoxy) ethyl 2methylpropanoate that have a broad antibacterial activity from a strain of Lactobacillus plantarum. Also, [9] obtained a bacteriocin-like compound that effectively inhibited grampositive and gram-negative tested organisms. They applied the sorption-desorption method, butanol extraction, and SEC-HPLC method. A $70 \%(\mathrm{v} / \mathrm{v})$ 2-propanol and $0.1 \%(\mathrm{v} / \mathrm{v})$ trifluoroacetic acid (TFA) extraction system was applied to get the antimicrobial compound mixture from Lactococcus lactis fermentate. The produced mixture showed inhibitory behavior against all of gram-positive such as Bacillus subtilis, Listeria innocua, Streptococcus pneumoniae and gram-negative like Pseudomonas aeruginosa [10]. Besides, [11] used Streptomyces lydicus metabolites to control the growth of Staphylococcus aureus and Bacillus cereus successfully. After extraction with different solvent systems, they found that aqueous fraction (methanolic) possessed the observed activity, while Ethyl acetate extract only exhibited a dose-dependent antioxidant activity. More recently, [12] applied the extraction of different antibacterial, antifungal, anticancer, hepato-protective substances from Lactobacillus helveticus using Head Space-Gas Chromatography/Mass Spectroscopy for extraction and analysis.

Considering the application of chitosan in dairy products, [13] used chitosan at the nanoscale that previously loaded with Natamycin for the packaging of cheese samples. They noted that treated samples significantly lowered their mold and yeast content than that of freestate Natamycin. In another assessment on milk-borne Staphylococcus aureus, [14] found that the activity of Nisin-loaded NPs exceeded the free Nisin by 50\%. Also, [15] found that Nisinloaded NPs effectively reduced Staphylococcus aureus and Listeria monocytogenes populations by at least five-fold log CFU than the free Nisin.

The main aim of this study was the chromatographic profiling of different extracts obtained from $L b$. helveticus CNRZ 32. After that, the antimicrobial potential of each extract was assessed through disc diffusion and Minimal inhibitory concentration.

\section{Materials and Methods}

\subsection{Materials.}

Nutrient agar was provided from Panreac Quimica, Spain; MRS agar was purchased from SRL, India; M17 agar was supplemented by CONDA, Spain; and Malt extract agar was imported from Biolife, Italy; Nisin (1100 IU/mg equivalent to $27.5 \mu \mathrm{g} / \mathrm{mg}$ ) was imported from Luoyang Chihon Biotechnology Co., Ltd, China; Natamycin (50\%) was imported from

Quimicas, Spain; Chitosan (M.W: 100.000 - 300.000) was purchased from ACROS ORGANICS, UK.

\subsection{Preparation of the cell-free supernatants (CFSs).}

About $250 \mathrm{ml}$ of MRS bottles were inoculated with $2 \%$ of LAB pure strains [4], and incubated at $30^{\circ} \mathrm{C}$ for 72 hours. CFSs were prepared by centrifugation of fermented media for $20 \mathrm{~min}$ at $7000 \mathrm{rpm}$ and kept at $4^{\circ} \mathrm{C}$ till use. 


\subsection{Characterization of the CFSs.}

\subsubsection{Antimicrobial activity.}

\subsubsection{Pathogenic and spoilage foodborne isolates.}

Pathogenic and food spoilage microorganisms; Escherichia coli strain E11 (accession number KY780346.1), Salmonella enterica strain SA19992307 (accession number CP030207.1), Pseudomonas aeruginosa strain Kasamber5 (accession number KY549641.1), Bacillus cereus strain 151007-R3-K09-40-27F (accession number KY820914.1), and Staphylococcus sciuri strain 2-6 (accession number MH491952.1), Penicillium chrysogenum strain J127 (KF572447.1) and Candida parapsilosis strain F2-17 (KP852497.1) were isolated and identified by Al-gamal et al. [4] from Egyptian cheese at Dairy Microbiological Lab., National Research Centre, Egypt.

\subsubsection{Disc diffusion technique.}

Antibacterial assay: the assay was performed as recommended in BSAC guidelines [16]. Briefly, from the overnight incubated culture, a typical colony was picked and introduced in a $5 \mathrm{ml}$ of tryptone soy broth. The broth culture was incubated at $35^{\circ} \mathrm{C}$ until visible turbidity reached 0.5 "McFarland" standard solution. Then, nutrient agar plates $(25 \mathrm{ml}$ agar $/ 9 \mathrm{~cm}$ plate or equivalent) were inoculated with sterile cotton swabs in three directions to finally give a semi-confluent growth after overnight incubation. Within 15 minutes, discs with tested substances were applied on the dried surface of the inoculated agar plates. After incubation at $35^{\circ} \mathrm{C}$ for $20 \mathrm{~h}$, inhibition zone diameters $(\mathrm{mm})$ were recorded.

Antifungal assay: Mold and yeast strains were plated onto Malt Extract Agar (MEA) and incubated for 3 days at $30^{\circ} \mathrm{C}$. The spore suspension of each fungus was prepared in $0.01 \%$ "tween 80 " solution by comparing it with the 0.5 "McFarland standard. Petri dishes containing MEA medium were inoculated as described above, and results were recorded after $48 \mathrm{~h}$.

Positive and negative controls: Dimethyl sulfoxide (DMSO) solution was considered as a negative control. Nisin $(100 \mathrm{mg} / \mathrm{ml})$ was used as the positive antibacterial control, while Natamycin $(100 \mu \mathrm{g} / \mathrm{ml})$ as the positive antifungal control.

\subsubsection{Determination of the Minimal Inhibitory Concentrations (MICs).}

Different extracts either in Free State or Nanoparticles were tested for MIC value. MICs were performed by the agar dilution method according to EUCAST protocol [17]. Briefly, molten agar tubes were allowed to cool in the water bath at $50^{\circ} \mathrm{C}$, and then supplemented with the accurately prepared dilution series of the tested substance, vortexed well, and poured in sterile pre-labeled Petri dishes. After complete dryness of the agar surface at room temperature, $1 \mu \mathrm{l}$ of $10^{7} \mathrm{CFU} / \mathrm{ml}$ of microbial suspension was inoculated. As recommended for disc diffusion, plates were incubated, and results were recorded.

2.3.2. Isolation and structure elucidation of bioactive compounds.

\subsubsection{Sample preparation and Gas Chromatography/Mass Spectroscopy analysis.}

The analysis was performed in chromatographic laboratory, central laboratories network, National Research Centre, Dokki, Egypt using a GC-MS system (7890A-5975C, Agilent Technologies Inc., Santa Rosa, CA, USA) equipped with an HP-5 MS capillary column 
(30 m $\times 0.25 \mathrm{~mm}, 0.25 \mathrm{~mm}$, Agilent Technologies Inc., Santa Rosa, CA, USA). The injection volume of the sample was $1 \mu \mathrm{L}$. Helium (99.999\%) was used as the carrier gas at $1 \mathrm{ml} / \mathrm{min}$ as flow-rate. The temperature of the injection port was $280{ }^{\circ} \mathrm{C}$, and the column temperature program was $40{ }^{\circ} \mathrm{C}$ for $5 \mathrm{~min}$, followed by an increase to $150{ }^{\circ} \mathrm{C}$ at a rate of $5^{\circ} \mathrm{C} / \mathrm{min}$, and an increase to $210^{\circ} \mathrm{C}$ at the rate of $10^{\circ} \mathrm{C} / \mathrm{min}$. The MS conditions Capillary column and 5975B Inert XL MS system under electron ionization at $70 \mathrm{eV}$ and Quadrupole mass analyzer. The MS source and Quadrupole were held at $230{ }^{\circ} \mathrm{C}$ and $150{ }^{\circ} \mathrm{C}$, respectively. Helium was used as carrier gas at $1 \mathrm{ml} / \mathrm{min}$. as a flow rate.

\subsection{Preparation and characterization of loaded-nanoparticles.}

Extracts-loaded Chitosan nanoparticles (Ch.-NPs) were prepared by dissolving 2 Grams of chitosan in $1 \%$ acetic acid solution. After complete dissolution, the chitosan solution was added drop wisely to the vigorously stirred Sodium Tripolyphosphate (TPP) solution $(0.03 \%)$. The resulted suspension was then subjected to sonication (DAIGGER Sonicator Model GEX 750, USA; sonication power, 750 Watts, frequency, $20 \mathrm{kHz}$ and amplitude $50 \%$, in Marine Toxins Lab., National Research Centre) for 30 minutes at $25^{\circ} \mathrm{C}$. Nanoparticles were stabilized by the addition of $0.4 \%$ Cetyltrimethylammonium bromide (CTAB) as a cationic surfactant.

The nanostructure of the samples was examined for suspensions of the corresponding nano-composites in water using a JEOL JEM-1400 transmission electron microscope (TEM) (at Research Park, Faculty of Agriculture, Cairo University) with an acceleration voltage of 80 $\mathrm{kV}$. The microscopy probes of the nano-composite samples were prepared by adding a small drop of the water dispersions onto a Lacey carbon film-coated copper grid, then allowing them to dry in air.

\subsection{Statistical analysis.}

Statistical significance was determined using Statistica Version 9 (State Soft, Tulsa, Okla., USA). The means were determined by analysis of variance test (ANOVA, two-way analysis $)(\mathrm{p}<0.05)[18]$.

\section{Results and Discussion}

\subsection{Evaluation of different solvent extracts of Lb. helveticus CFS.}

In order to get the concentrated bioactive compounds, CFS was introduced for extraction with four organic solvents; n-Hexane, Dichloromethane, Ethyl acetate, and Diethyl ether. Furthermore, the solvent residues were then excluded through rotary evaporation. After complete evaporation of the solvent residues, extracts were tested for their antimicrobial potential through disc diffusion assay.

\subsubsection{Disc diffusion technique.}

The results presented in Table 1 summarize the antimicrobial effects of different extracts through disc diffusion. Ethyl acetate extract possessed the strongest effect on all tested pathogens with inhibition diameter ranged from $38 \mathrm{~mm}$ for Staphylococcus sciuri to $12 \mathrm{~mm}$ in the case of Candida parapsilosis, resembling about $80 \%$ of the positive antifungal control; 
Natamycin and 506\% of the antibacterial positive control activities. The both of Diethyl ether and Dichloromethane extracts came secondly, while n-Hexane showed a very slight inhibition.

Table 1. Inhibitory potential of different solvent extracts on cheese-borne microorganisms.

\begin{tabular}{|c|c|c|c|c|c|c|c|}
\hline \multirow[b]{2}{*}{$\begin{array}{c}\text { Crude } \\
\text { extracts }\end{array}$} & \multicolumn{7}{|c|}{ Inhibition zone diameters (mm) } \\
\hline & 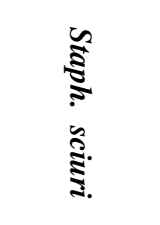 & 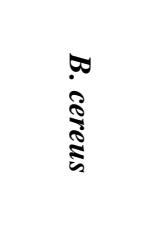 & 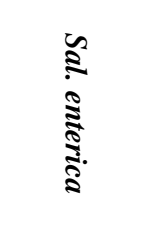 & $\begin{array}{l}N \\
\vdots \\
\vdots\end{array}$ & 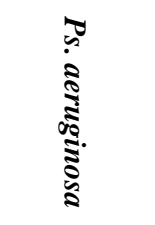 & 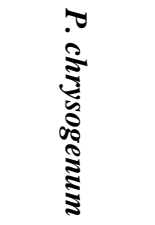 & 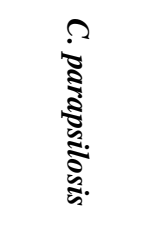 \\
\hline Ethyl acetate & $38 \pm 2.30^{\mathrm{H}}$ & $36 \pm 2.50^{\mathrm{H}}$ & $31 \pm 2.50^{\mathrm{K}}$ & $23 \pm 2.10^{\mathrm{B}}$ & $14 \pm 1.00^{\mathrm{C}}$ & $15 \pm 0.05^{\mathrm{C}}$ & $12 \pm 0.25^{\mathrm{D}}$ \\
\hline Diethyl ether & $21 \pm 1.05^{\mathrm{B}}$ & $25 \pm 1.75^{\mathrm{B}}$ & $15 \pm 0.75^{\mathrm{C}}$ & $10 \pm 0.05^{\mathrm{G}}$ & $18 \pm 1.05^{\mathrm{F}}$ & $12 \pm 0.05^{\mathrm{D}}$ & $10 \pm 0.02^{\mathrm{G}}$ \\
\hline n-Hexane & $6 \pm 0.05^{\mathrm{A}}$ & $6 \pm 0.05^{\mathrm{A}}$ & ND & ND & $6 \pm 0.05^{\mathrm{A}}$ & ND & ND \\
\hline Dichloromethane & $22 \pm 1.50^{\mathrm{B}}$ & $21 \pm 2.00^{\mathrm{B}}$ & $15 \pm 0.50^{\mathrm{C}}$ & $10 \pm 0.09^{\mathrm{G}}$ & $13 \pm 0.49^{\mathrm{D}}$ & $16 \pm 0.55^{\mathrm{C}}$ & $13 \pm 0.75^{\mathrm{C}}$ \\
\hline Nisin & $7.5 \pm 0.05$ & $7 \pm 0.05^{\mathrm{E}}$ & $\mathrm{ND}$ & ND & ND & NT & NT \\
\hline Natamycin & NT & NT & NT & NT & NT & $17 \pm 1.00^{\mathrm{C}}$ & $15 \pm 1.00^{\mathrm{C}}$ \\
\hline Negative Control & ND & ND & ND & ND & ND & ND & ND \\
\hline
\end{tabular}

Data expressed as Mean \pm Standard error; all columns or rows of the different letter are significantly different at P <0.05; ND: non-detected inhibition; and NT: Not Tested

\subsubsection{Transmission Electron Microscope imaging of chitosan nanoparticles.}

The size and morphology of prepared chitosan Nanoparticles were shown in Figure 1. The particles appeared to be spherical, with size ranged from $14.6 \mathrm{~nm}$ to $18.5 \mathrm{~nm}$.

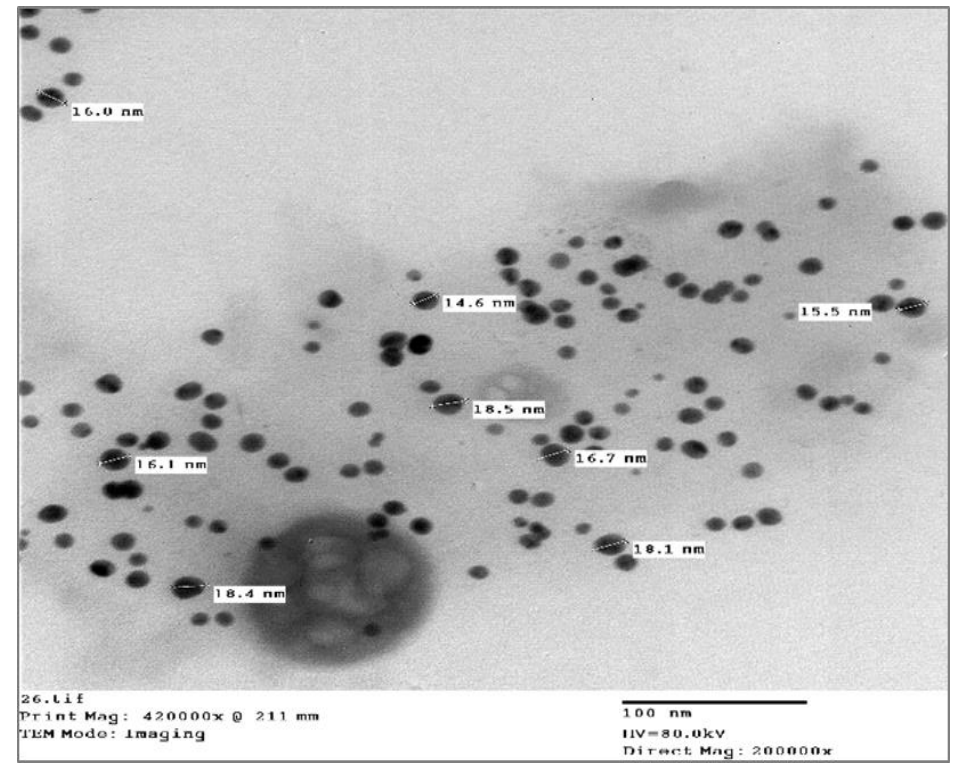

Figure 1. TEM micrograph of Natamycin loaded-Chitosan Nanoparticles.

\subsubsection{Estimation of the minimal inhibitory concentrations (MICs).}

This assay aimed to estimate the MICs for the most potent crude extracts; ethyl acetate, diethyl ether, and dichloromethane either in Free State or as loaded on Chitosan Nanoparticles. Tables $2 \& 3$ summarize the extract-specific MIC values against the cheese-borne indicator microorganisms, all in comparison with Nisin as the positive antibacterial control and Natamycin as the positive antifungal control. 
As presented in Tables $2 \& 3$, the loading of active extracts on Ch. NPs. lowered the MIC values against hosted bacteria from $0.25 \mathrm{mg} / \mathrm{ml}$ to $0.2 \mathrm{mg} / \mathrm{ml}(\sim 20 \%)$ for both Ethyl acetate and Diethyl ether extracts, while reached to $40-50 \%$ in case of Dichloromethane extract. Only in the case of Salmonella enterica, the reduction of MIC values reached 50, 60, and $70 \%$ for Ethyl acetate, Diethyl ether extracts, and dichloromethane extracts, respectively. It is also noted that the effective Nisin concentration was lowered from 50 to $62.5 \%$. The observed synergistic effect of Nisin or such antibacterial cationic peptide and Chitosan Nanoparticles combination was agreed by many previous researches [19]. By following up Staphylococcus aureus count, Lee et al. [20] observed about $29 \%$ count reduction caused by Nisin loaded chitosan NPs more than free Nisin. This may be clarified by the increased contact surface of densely charged cationic chitosan NPs which bind the anionic cell membrane causing disruption of its function, consequently lowered the concentration of Nisin that causes inhibition of wall synthesis and formation of pores in the cell membrane. As a result, cellular components leak out, causing cell death. The ineffective contribution of Free Nisin to gramnegative bacterial inhibition was established by Vukomanović et al. [21]. They also attributed the current noticed inhibitory effect of Nisin (Table 3) against both Escherichia coli and Pseudomonas aeruginosa to the synergism between Nisin and Nanoparticles. The nanostructure gives spherical Nisin, increasing contact area within cell membranes. In addition, the high concentrations of Nisin were proved to induce cell membrane distortion through the high surface-bound density of Nisin that increases the membrane tension.

For antifungal MIC values, the greater reduction in MIC (70\%) was observed in Ch. NPs.-loaded Natamycin. Both ethyl acetate and Diethyl ether extracts showed $50 \%$ reduced MICs in the case of Penicillium chrysogenum, while dichloromethane gave only about $17 \%$ reduction. Candida parapsilosis that possessed a slight reduction in MICs for loaded extracts $(17-25 \%)$ even for the positive control (0\%), appeared more resistant than Penicillium chrysogenum.

Table 2. MIC values of crude extracts in free states against indicator strains.

\begin{tabular}{l|c|c|c|c}
\multirow{2}{*}{\multicolumn{1}{c}{ Tested bacteria }} & \multicolumn{3}{c|}{ Free Extract $(\mathbf{m g} / \mathbf{m l})$} & \multirow{2}{*}{$\begin{array}{c}\text { Control positive } \\
(\mathbf{m g} / \mathbf{m l})\end{array}$} \\
\cline { 2 - 4 } Staphylococcus sciuri & Ethyl acetate & Diethyl ether & Dichloromethane & $0.6 \pm 0.05^{\mathrm{C}}$ \\
\hline Bacillus cereus & $0.25 \pm 0.01^{\mathrm{A}}$ & $0.25 \pm 0.01^{\mathrm{A}}$ & $0.5 \pm 0.02^{\mathrm{C}}$ & $0.8 \pm 0.10^{\mathrm{D}}$ \\
\hline Salmonella enterica & $0.25 \pm 0.02^{\mathrm{A}}$ & $0.25 \pm 0.01^{\mathrm{A}}$ & $1 \pm 0.05^{\mathrm{B}}$ & $\mathrm{ND}$ \\
\hline Escherichia coli & $0.25 \pm 0.01^{\mathrm{A}}$ & $0.25 \pm 0.01^{\mathrm{A}}$ & $0.5 \pm 0.05^{\mathrm{C}}$ & $\mathrm{ND}$ \\
\hline Pseudomonas aeruginosa & $0.25 \pm 0.02^{\mathrm{A}}$ & $0.25 \pm 0.01^{\mathrm{A}}$ & $1 \pm 0.10^{\mathrm{B}}$ & $\mathrm{ND}$ \\
\hline Penicillium chrysogenum & $3 \pm 0.02^{\mathrm{A}}$ & $0.25 \pm 0.01^{\mathrm{A}}$ & $1 \pm 0.05^{\mathrm{B}}$ & $0.01 \pm 0.00^{\mathrm{E}}$ \\
\hline Candida parapsilosis & $6 \pm 0.00^{\mathrm{B}}$ & $2 \pm 0.00^{\mathrm{C}}$ & $3 \pm 0.25^{\mathrm{A}}$ & $0.00^{\mathrm{D}}$ \\
\hline
\end{tabular}

Data expressed as Mean \pm Standard error; all columns or rows of the different letter are significantly different $(\mathrm{P}<0.05)$, ND: Not detected.

Table 3. MIC values of crude extracts-loaded Ch. NPs., against bacterial indicator strains.

\begin{tabular}{l|c|c|c|c}
\multirow{2}{*}{\multicolumn{1}{c}{ Tested bacteria }} & \multicolumn{2}{c}{ Extract-loaded Ch. NPs. (mg/ml) } & \multirow{2}{*}{$\begin{array}{c}\text { Control positive } \\
(\mathbf{m g} / \mathbf{m l})\end{array}$} \\
\cline { 2 - 4 } Staphylococcus sciuri & Ethyl acetate & Diethyl ether & Dichloromethane & $0.3 \pm 0.00^{\mathrm{D}}$ \\
\hline Bacillus cereus & $0.2 \pm 0.00^{\mathrm{A}}$ & $0.2 \pm 0.00^{\mathrm{A}}$ & $0.3 \pm 0.00^{\mathrm{D}}$ & $0.3 \pm 0.00^{\mathrm{D}}$ \\
\hline Salmonella enterica & $0.2 \pm 0.00^{\mathrm{A}}$ & $0.2 \pm 0.00^{\mathrm{A}}$ & $0.6 \pm 0.00^{\mathrm{E}}$ & $\mathrm{ND}$ \\
\hline Escherichia coli & $0.125 \pm 0.00^{\mathrm{B}}$ & $0.1 \pm 0.00^{\mathrm{C}}$ & $0.15 \pm 0.00^{\mathrm{N}}$ & $20 \pm 0.00^{\mathrm{R}}$ \\
\hline Pseudomonas aeruginosa & $0.2 \pm 0.00^{\mathrm{A}}$ & $0.2 \pm 0.00^{\mathrm{A}}$ & $0.5 \pm 0.00^{\mathrm{G}}$ & $30 \pm 1.00^{\mathrm{S}}$ \\
\hline Penicillium chrysogenum & $2 \pm 0.00^{\mathrm{A}}$ & $0.2 \pm 0.00^{\mathrm{A}}$ & $0.6 \pm 0.00^{\mathrm{E}}$ & $0.003 \pm 0.00^{\mathrm{F}}$ \\
\hline Candida parapsilosis & $5 \pm 0.10^{\mathrm{B}}$ & $3.25 \pm 0.10^{\mathrm{C}}$ & $2.5 \pm 0.10^{\mathrm{E}}$ & $0.005 \pm 0.00^{\mathrm{G}}$
\end{tabular}

Data expressed as Mean \pm Standard error; all columns or rows of the different letter are significantly different $(\mathrm{P}<0.05)$, Ch. NPs: Chitosan nanoparticles. 
The enhanced effect of Natamycin upon loading on NPs. was noticed by [22] to reach 2.5 times free Natamycin. As explained formerly, the high density of positively-charged $\mathrm{Ch}$. NPs. enables particles to bind effectively with the negatively-charged fungal cell membranes. Furthermore, the small size of NPs. allows them to diffuse easily into microbial cells and get their way to the nuclear area causing denaturation of both DNA and RNA [23].

\subsection{Bioautographic studying of crude extracts.}

Crude extracts were separately subjected to Thin Layer Chromatographic (TLC) silica gel plates to get partially separated. After complete dryness, plates were taken out to distinguish bands by visual detection under UV light $(254 \mathrm{~nm})$. The developed bands were marked using a lead pencil, and the $R_{\mathrm{f}}$ values were calculated. $R_{\mathrm{f}}$ value can be defined as the distance traveled by a certain band, divided by the total distance from the base-line to the end-line.

The inhibitory range of bio-autographic TLC plates on microbial growth was presented in Figure 2 and Table 4. They present the selected solvent system, number, and $R_{f}$ of bands/spots of every crude extract with their target microorganisms. After separation of the 3 active extracts on TLC plates, the bands were visualized and marked under UV light ( $254 \mathrm{~nm})$.

As shown, each extract included at least two antimicrobial active bands, at the same time, all pathogens were inhibited by two or more bands except Candida parapsilosis that inhibited only by the extracts as it is. These results can be explained when the components of the extracts get identified via instrumental facilities.

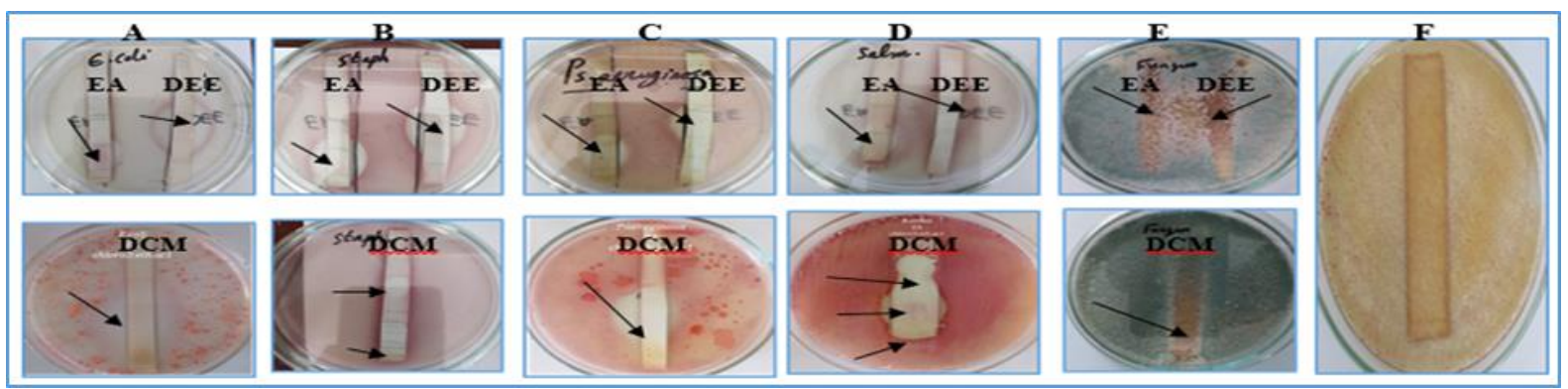

A: E. coli; B: Staph. sciuri; C:Ps. aeruginosa; D: Salmonella enterica; E: Penicillium chrysogenum; F: Candida parapsilosis; EA: ethyl acetate extract; DEE: diethyl ether extract; DCM: dichloromethane extract

Figure 2. The inhibition of microbial growth on bio-autographic TLC plates.

Table 4. The inhibitory range of bio-autographic TLC plates on microbial growth.

\begin{tabular}{|c|c|c|c|c|}
\hline $\begin{array}{c}\text { Extract } \\
1 \\
\end{array}$ & $\begin{array}{l}\text { Solvent } \\
\text { system }\end{array}$ & $\begin{array}{c}\text { No. of active } \\
\text { bands }\end{array}$ & $\mathbf{R}_{\mathbf{f}}$ & Target organism \\
\hline \multirow{6}{*}{ 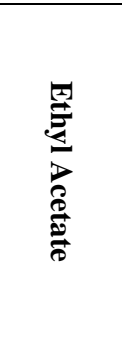 } & \multirow{6}{*}{$\begin{array}{c}\text { Chloroform : EA } \\
(1: 1)\end{array}$} & 5 & $\begin{array}{c}0.45,0.49,0.54,0.58 \\
0.63\end{array}$ & Pseudomonas aeruginosa \\
\hline & & 4 & $0.45,0.49,0.54,0.58$ & $\begin{array}{l}\text { Escherichia coli \& } \\
\text { Salmonella enterica }\end{array}$ \\
\hline & & 4 & $0.54,0.58,0.63,0.74$ & Bacillus cereus \\
\hline & & 5 & $\begin{array}{c}0.45,0.49,0.54,0.58 \\
0.63\end{array}$ & Staphylococcus sciuri \\
\hline & & 2 & $0.63,0.74$ & Penicillium Chrysogenum \\
\hline & & ND & $\begin{array}{ll}-- \\
\end{array}$ & Candida Parapsilosis \\
\hline
\end{tabular}

\subsection{GC/MS analysis of crude extracts.}

In this part, the volatile profiles of the three effective extracts; Ethyl acetate, Diethyl ether, and dichloromethane, were illustrated. GC/MS analysis was used to inspect the components of crude extracts. The GC/MS chromatogram, as well as mass spectra of the most abundant compounds for each extract, was also demonstrated. 
Metabolic profiling was summarized in Table 5 that shows the names of the abundant components along with their retention times, area $\%$, and molecular formulas.

Table 5. Metabolic profiling of the crude extracts using GC/MS.

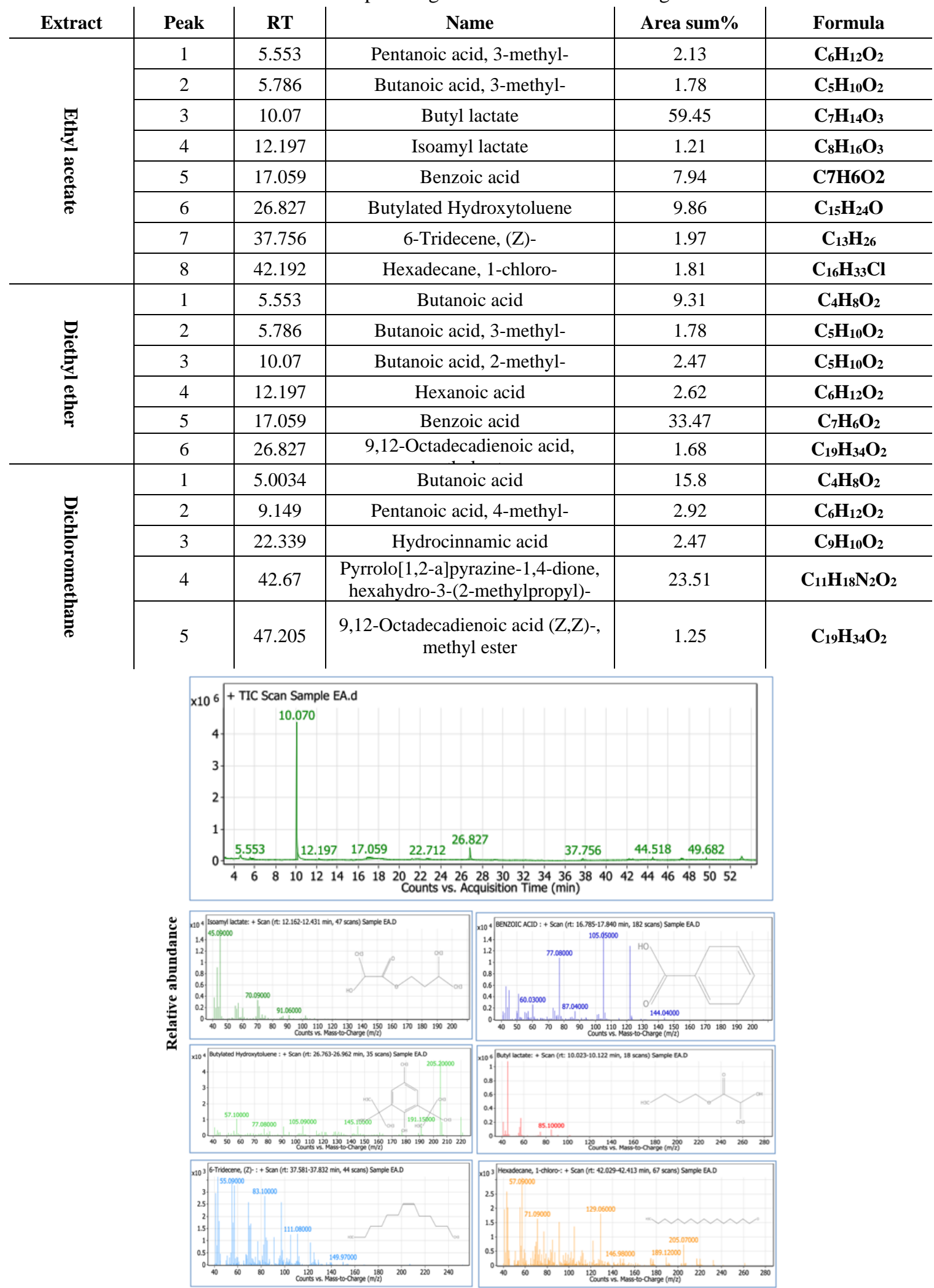

Figure 3. GC/MS Spectral Chromatogram and mass spectra of ethyl acetate extract.

As observed in Table 5, Ethyl acetate extract included butyl lactate with area \% (59.45), butylated hydroxytoluene $(9.86 \%)$, benzoic acid (7.94\%), pentanoic acid, 3-methyl- (2.13\%), 6-tridecene, (Z)- (1.97\%), hexadecane, 1-chloro- (1.81\%), butanoic acid, and 3-methyl- 
$(1.78 \%)$, isoamyl lactate $(1.21 \%)$. The GC/MS chromatogram and mass spectra of the most common compounds were illustrated in Figure 3.

For diethyl ether extract, the commonly detected compounds included benzoic acid (33.7\%), butanoic acid (9.31\%), hexanoic acid (2.62\%), butanoic acid, 2-methyl- (2.47\%), butanoic acid, 3-methyl- (1.78\%), and 9,12-octadecadienoic acid, methyl ester (1.68\%). The GC/MS chromatogram and mass spectra of the common compounds were shown in Figure 4.

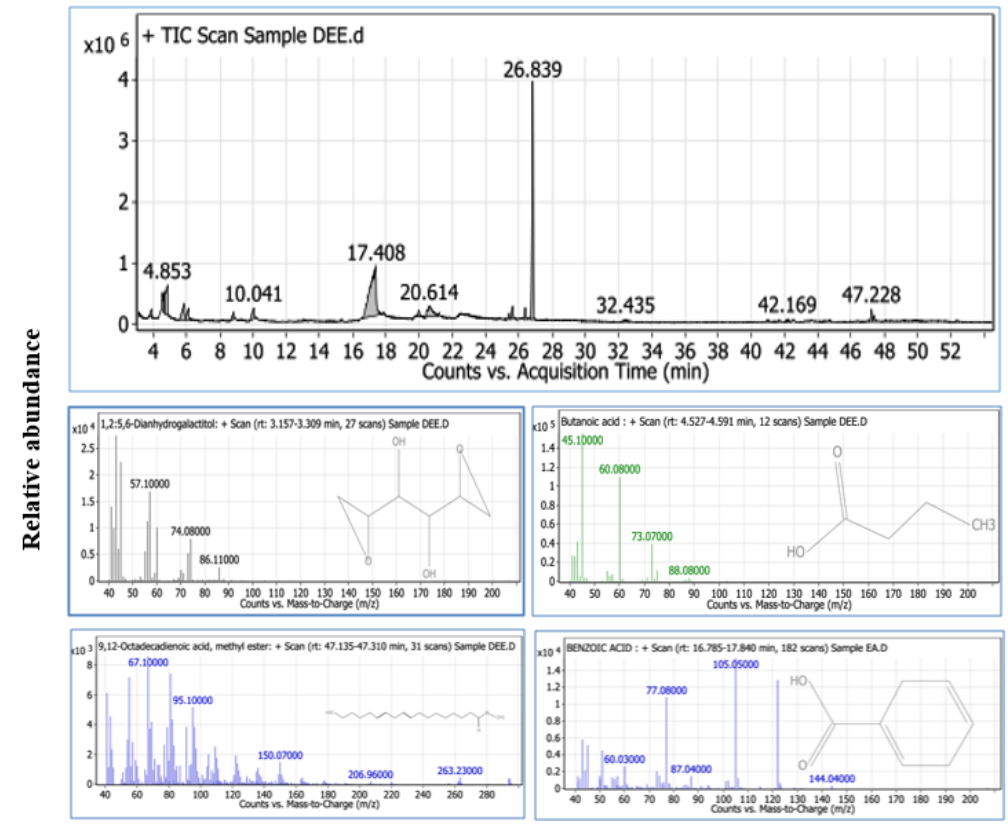

Figure 4. GC/MS Spectral chromatogram and mass spectra of diethyl ether extract.

As seen in Figures 5, dichloromethane extract was reported to contain pyrrolo [1,2-a] pyrazine -1,4-dione,hexahydro-3- (2-methylpropyl)- (23.51\%), butanoic acid (15.8\%), pentanoic acid, 4-methyl- (2.92\%), hydrocinnamic acid (2.47\%), and 9,12-octadecadienoic acid (Z,Z)-, methyl ester (1.25\%).

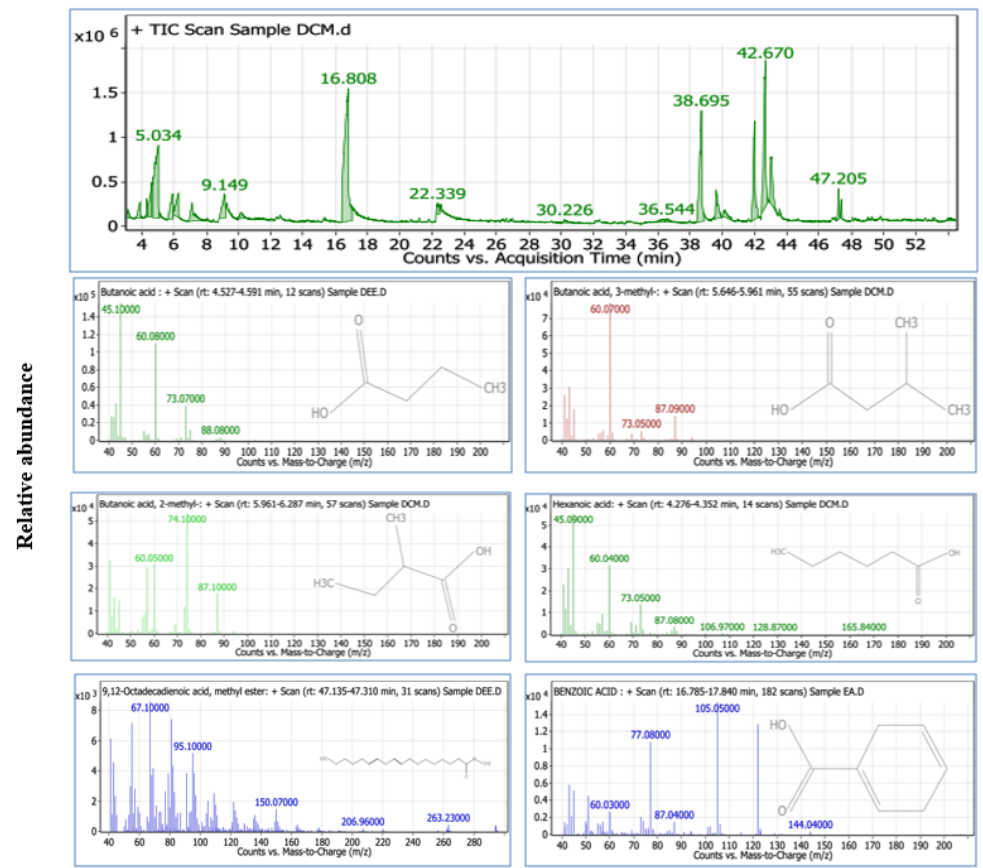

Figure 5. GC/MS Spectral Chromatogram and mass spectra of dichloromethane extract. 
The bioactivity of these compounds, either as antimicrobial, or health promoters, was described in the literature by many researchers. Kavčič et al. [24] reported the excellent activity of n-butyl lactate, a form of lactic acid produced by Lactic acid bacteria against many potential pathogenic bacteria and spoilage yeasts and fungi. Their results revealed that n-butyl lactate could completely inhibit the mycelial growth of such Aspergillus niger and Penicillium sp., while having a high inhibitory potential against Escherichia coli, Pseudomonas sp., and Bacillus cereus. In addition, Zhang et al. [25] confirmed the role of Butylated Hydroxytoluene in retarding of pathogenic and spoilage growth, along with acting as a good antioxidant. Deepa et al. [26] reviewed the great contribution of Butanoic acid to retard the growth of Salmonella $s p$. in broiler chicken production stations. In addition, Adeyemi et al. [27] referred to the significant health beneficial role of 9,12- Octadecadienoic acid (Z,Z)-, methyl ester. As reported, this compound showed a good anti-inflammation, anticancer, hypocholesterolemic, hepato-protection, and antimicrobial activity. It is important to state that the highest content of this health-beneficial compound was currently observed in the Diethyl ether extract. In addition, all extracts were seen to be more effective and wider spectra either against bacteria, gram-positive and gram-negative or against yeasts and fungi than Nisin alone and Natamycin alone. Furthermore, these bio-protective LAB extracts were proven to contain diverse biologically active compounds.

The collective view found that the greatest inhibition zones were obtained in the case of gram-positive pathogens (Table 1), the multi-active bio-autographic bands in gram-positive bacterial pathogens (Figure 2) among all pathogenic bacteria, fungi, and yeasts. Inclusion of bacteriocins in all extracts may come in the front of all suggestions. Lv et al. [28] successfully extracted a bacteriocin from Lactobacillus plantarum using ethyl acetate solvent. In addition, the considerable content of organic acids supports the antimicrobial activity.

\section{Conclusions}

Lactobacillus helveticus CNRZ 32 exhibited inhibitory activity against different microbial pathogens and food spoilers. In addition to bacteriocins, this bacterium could synthesize a wide range of metabolites that antagonize many microbial concerns. The results suggest the synergistic relationship between Ch. NPs. and Lactobacillus helveticus-based antimicrobials that lowered the MIC value by 20 - 50\%, but still less than the loaded Natamycin. The antibacterial, antifungal, and health-promoting potentials of Lactobacillus helveticus CNRZ 32, and its metabolic reservoir could make them an efficient alternative to both Nisin and Natamycin in dairy industries.

\section{Funding}

This research was funded by the National Research Centre (NRC) under the code of (4/1/16).

\section{Acknowledgments}

I would like to thank all respectful colleagues in Marine Toxin Lab. for their helpful aid in improving the part of chromatography.

\section{Conflicts of Interest}

The authors declare no conflict of interest. 


\section{References}

1. Khan, N.; Hassan, A.; Ullah, H.; Akmal, Z.; Khan, M.Y.; Khan, S.U. Antibacterial potential test for Scheonoplectus Triqueter (L) Palla. Lett. In Appl. NanoBioSci. 2020. 9, 941-944, https://doi.org/10.33263/LIANBS91.941944.

2. Saranya, S.; Hemashenpagam, N. Antagonistic activity and antibiotic sensitivity of lactic acid bacteria from fermented dairy products. Adv. in Appl. Sci. Res. 2011, 2, 528-534.

3. Cheong, E.Y.; Sandhu, A.; Jayabalan, J.; Le, T.T.K.; Nhiep, N.T.; Ho, H.T.M.; Zwielehner, J.; Bansal, N.; Turner, M.S. Isolation of lactic acid bacteria with antifungal activity against the common cheese spoilage mould Penicillium commune and their potential as biopreservatives in cheese. Food Cont. 2014, 46, 91-97, https://doi.org/10.1016/j.foodcont.2014.05.011.

4. Al-Gamal, M.S.; Ibrahim, G.A.; Sharaf, O.M.; Radwan, A.A.; Dabiza, N.M.; Youssef, A.M.; El-Ssayad, M.F. The protective potential of selected lactic acid bacteria against the most common contaminants in various types of cheese in Egypt. Heliyon 2019, 5, https://doi.org/10.1016/j.heliyon.2019.e01362.

5. Kanayama, M.; Kato, Y.; Tsuji, T.; Konoeda, Y.; Hashimoto, A.; Kanauchi, O.; Fujii, T.; Fujiwara, D. Enhancement of immunomodulative effect of lactic acid bacteria on plasmacytoid dendritic cells with sucrose palmitate. Sci. rep. 2018, 8, 1-12, https://doi.org/10.1038/s41598-018-21527-2.

6. Castellano, P.; Pérez Ibarreche, M.; Blanco Massani, M.; Fontana, C.; Vignolo, G. Strategies for pathogen biocontrol using lactic acid bacteria and their metabolites: a focus on meat ecosystems and industrial environments. Microorganisms 2017, 5, https://doi.org/10.3390/microorganisms5030038.

7. Deepthi, B.V.; Rao, K.P.; Chennapa, G.; Naik, M.K.; Chandrashekara, K.T.; Sreenivasa, M.Y. Antifungal attributes of Lactobacillus plantarum MYS6 against fumonisin producing Fusarium proliferatum associated with poultry feeds. PloS one 2016, 11, https://doi.org/10.1371/journal.pone.0155122.

8. Lin, T.H.; Pan, T.M.Characterization of an antimicrobial substance produced by Lactobacillus plantarum NTU 102. Journal of Microbiol., Immun. and Inf. 2017, 52, 409-417, https://doi.org/10.1016/j.jmii.2017.08.003.

9. De Giani, A.; Bovio, F.; Forcella, M.; Fusi, P.; Sello, G.; Di Gennaro, P. Identification of a bacteriocin-like compound from Lactobacillus plantarum with antimicrobial activity and effects on normal and cancerogenic human intestinal cells. AMB Express 2019, 9, https://doi.org/10.1186/s13568-019-0813-6.

10. Saraiva, M.A.F.; Brede, D.A.; Nes, I.F.; Baracat-Pereira, M.C.; de Queiroz, M.V.; de Moraes, C.A. Purification and characterization of two new cell-bound bioactive compounds produced by wild Lactococcus lactis strain. FEMS microbial. Let. 2017, 364, https://doi.org/10.1093/femsle/fnx130.

11. Lertcanawanichakul, M.; Pondet, K.; Kwantep, J. In vitro antimicrobial and antioxidant activities of bioactive compounds (secondary metabolites) extracted from Streptomyces lydicus A2. J. of Appl. Pharm. Sci. 2015, 5, 17-21, https://doi.org/10.7324/JAPS.2015.50204.

12. Sharaf, O.M.; Al-Gamal, M.S.; Ibrahim, G.A.; Dabiza, N.M.; Salem, S.S.; El-Ssayad, M.F.; Youssef, A.M. Evaluation and characterization of some protective culture metabolites in free and nano-chitosan-loaded forms against common contaminants of Egyptian cheese. Carbohyd. Pol. 2019, 223, https://doi.org/10.1016/j.carbpol.2019.115094.

13. Santonicola, S.; García Ibarra, V.; Sendón, R.; Mercogliano, R.; Rodríguez-Bernaldo de Quirós, A. Antimicrobial films based on chitosan and methylcellulose containing natamycin for active packaging applications. Coatings 2017, 7, https://doi.org/10.3390/coatings7100177.

14. Zohri, M.; Alavidjeh, M.S.; Haririan, I.; Ardestani, M.S.; Ebrahimi, S.E.S.; Sani, H.T.; Sadjadi, S.K. A comparative study between the antibacterial effect of Nisin and nisin-loaded chitosan/alginate nanoparticles on the growth of Staphylococcus aureus in raw and pasteurized milk samples. Prob. Antimicrob. Prot. 2010, 2, 258-266, https://doi.org/10.1007/s12602-010-9047-2.

15. Zohri, M.; Shafiee Alavidjeh, M.; Mirdamadi, S.S.; Behmadi, H.; Hossaini Nasr, S.M.; Eshghi Gonbaki, S.; Shafiee Ardestani, M.; Jabbari Arabzadeh, A. Nisin-Loaded Chitosan/Alginate Nanoparticles: A Hopeful Hybrid Biopreservative. J. of Food safety 2013, 33, 40-49, https://doi.org/10.1111/jfs.12021.

16. Andrews, J.M. BSAC standardized disc susceptibility testing method (version 4). J. of antimicrob. Chemoth. 2005, 56, 60-76, https://doi.org/10.1093/jac/dki124.

17. European Committee for Antimicrobial Susceptibility Testing (EUCAST) of the European Society of Clinical Microbiology and Infectious Diseases (ESCMID). Determination of minimum inhibitory concentrations (MICs) of antibacterial agents by agar dilution. Clin. Microbiol. Inf. 2000, 6, 509-515, https://doi.org/10.1046/j.1469-0691.2000.00142.x.

18. Williams, L.; Abdi, H. Fisher's least significant difference test. Encyclo. of res. Des. 2010, 492-495.

19. Tamara, F.R.; Lin, C.; Mi, F.L.; Ho, Y.C. Antibacterial effects of chitosan/cationic peptide nanoparticles. Nanomater. 2018, 8, 88, https://doi.org/10.3390/nano8020088.

20. Lee, E.H.; Khan, I.; Oh, D.H. Evaluation of the efficacy of nisin-loaded chitosan nanoparticles against foodborne pathogens in orange juice.J. of food sci. technol. 2018, 55, 1127-1133, https://doi.org/10.1007/s13197-017-3028-3. 
21. Vukomanović, M.; Žunič, V.; Kunej, Š.; Jančar, B.; Jeverica, S.; Suvorov, D. Nano-engineering the antimicrobial spectrum of lantibiotics: activity of Nisin against gram negative bacteria. Sci. rep. 2017, 7, https://doi.org/10.1038/s41598-017-04670-0.

22. Khames, A.; Khaleel, M.A.; El-Badawy, M.F.; El-Nezhawy, A.O. Natamycin solid lipid nanoparticlessustained ocular delivery system of higher corneal penetration against deep fungal keratitis: preparation and optimization. Internat. J. of nanomed. 2019, 14, https://doi.org/10.2147/IJN.S190502.

23. Yien, L.; Zin, N.M.; Sarwar, A.; Katas, H. Antifungal activity of chitosan nanoparticles and correlation with their physical properties. Internat. J. of Biomat. 2012, 2012, https://doi.org/10.1155/2012/632698.

24. Kavčič, S.; Knez, Ž.; Leitgeb, M. Antimicrobial activity of n-butyl lactate obtained via enzymatic esterification of lactic acid with n-butanol in supercritical trifluoromethane. J. of Supercrit. Flu. 2014, 85, 143-150, https://doi.org/10.1016/j.supflu.2013.11.003.

25. Zhang, H.; Wu, J.; Guo, X. Effects of antimicrobial and antioxidant activities of spice extracts on raw chicken meat quality. Food Sci. Hum. Well. 2016, 5, 39-48, https://doi.org/10.1016/j.fshw.2015.11.003.

26. Deepa, K.; Purushothaman, M.R.; Vasanthakumar, P.; Sivakumar, K. Butyric acid as an antibiotic substitute for broiler chicken-A review. Adv. in Animal Vet. Sci. 2018, 6, 63-69, https://doi.org/10.17582/journal.aavs/2018/6.2.63.69.

27. Adeyemi, M.A.; Ekunseitan, D.A.; Abiola, S.S.; Dipeolu, M.A.; Egbeyale, L.T.; Sogunle, O.M. Phytochemical Analysis and GC-MS Determination of Lagenaria breviflora R. Fruit. Internat. J. of Pharmacog. Phytochem. Res. 2017, 9, 1045-1050, https://doi.org/10.25258/phyto.v9i07.11178.

28. Lv, X.; Miao, L.; Ma, H.; Bai, F.; Lin, Y.; Sun, M.; Li, J. Purification, characterization and action mechanism of plantaricin JY22, a novel bacteriocin against Bacillus cereus produced by Lactobacillus plantarum JY22 from golden carp intestine. Food sci. biotechnol. 2018, 27, 695-703, https://doi.org/10.1007/s10068-0170280-2. 